\title{
Health, Place and Hanly: modelling accessibility to hospitals in Ireland
}

\author{
Stamatis Kalogirou ${ }^{1}$ and Ronan Foley ${ }^{2}$ \\ ${ }^{1}$ National Centre for Geocomputation and ${ }^{2}$ Department of Geography, \\ National University of Ireland, Maynooth.
}

\begin{abstract}
The Irish Government is currently engaged in considerations about a proposed reorganisation of acute hospital services. The proposals in the 'Hanly' Report recommend the creation of new classifications of Major, General and Local Hospitals. This paper looked at how these proposals might affect geographical accessibility to Irish acute hospitals and modelled it within a GIS framework. Spatial data in the form of hospital location and size, road network and demographic distribution of over 65 's were drawn together within the GIS. A weighted accessibility formula was applied to produce a measure of accessibility called a Spatial Accessibility Measure based on travel time, hospital size and population-weighting. This measures was then applied to produce three scenarios modelled on; a) the existing configuration of services, b) a partial roll-out and c) a full roll-out of the proposed changes in the 'Hanly' Report. The scenarios identified those parts of the country, which were potentially likely to have increased/decreased accessibility to acute hospital services based on the different scenarios. Residents in the central and western parts of the country were shown to be most vulnerable, while the impacts of a full roll-out of Hanly suggests additional potential impacts on some suburban hospitals in the Greater Dublin area. The work provides a valuable and previously underdeveloped set of policy-informed spatial outcomes which can be adjusted if or when more beds are introduced into the Irish health care system in the next five to ten years.
\end{abstract}

Key index words: healthcare, accessibility, service planning, GIS, policy.

\section{Introduction}

The Irish Government is currently in the process of planning the strategic reformation of the existing structure of acute hospital services across the country. This process has been developed through a series of strategic government reports linked to wider health care reform and specific hospital reorganisation (Department of Health and Children, 2001, Department of Health and Children, 2002, Prospectus Strategy Consultants, 2003). For hospital services, a particularly relevant policy document is one that is widely referred to as the Hanly Report (Department of Health and Children, 2003). The essential thrust of the Hanly Report is to suggest planned efficiency changes in current acute hospital provision. While driven by a EU working-time directive on medical staffing, the report also took the opportunity to suggest changes in the configuration of acute hospital provision (European Union, 2000). The key changes suggested by the Hanly Report are based around expanding services in existing large regional centres (Major Hospitals) while downgrading services in sub-regional centres (Local Hospitals). This major shift in policy and service provision would seem to lend itself to areabased modelling to clarify the implications of the planned changes.

To date, there has been limited GIS-based modelling carried out at a national level in Ireland with regard to the existing system of either acute or more general hospital provision.

Irish Geography, Volume 39(1), 2006, 52-68. 
It is imperative therefore, that a number of area-based models of service provision are developed to identify the implications of current and proposed new structures (Teljeur, Barry and Kelly, 2004). From a policy perspective, this may prove especially valuable in the light of considerable local resistance to the proposed hospital changes, a factor common in most change environments (Brownell et al., 2001; Luo and Wang, 2003; MacNamara, 2004). As an exemplar of this process, this paper therefore aims to initially model existing access to acute hospital services: Additionally, to augment accessibility modelling for the population as a whole, the work will also look briefly at the elderly population as a sample group. The choice of people over the age of 65 is relevant in that the literature clearly identifies this group as being the main users of acute hospital services (Gatrell, 2002). The choice of the elderly also enables the modelling of specialist geriatric service provision as a contrast to the wider general provision. The second main aim of the paper is to use GIS to model a set of theoretical scenarios as to how the planned changes within Hanly may affect accessibility to acute services within the state as a whole.

\section{Literature Review}

There is a considerable literature on the measurement and modelling of health care service provision in different parts of the developed world. The literature on service provision can be broadly summarised under two broad headings, the mapping of service provision and the modelling of accessibility to, and utilisation of, services. Work in both these areas ranges from the original seminal work of Joseph and Phillips (1984) to recent studies in the UK, South Africa, the US and Australasia (Bhana and Pillay, 1998; O'Dwyer and Burton, 1998; Rushton, 1999; Phillips et al., 2000; Lovett et al., 2002). This literature review will focus on a number of papers, which seem to have particular relevance to this work as well as identifying the relatively limited work using GIS within the Irish health care environment. Within the wider literature it is also important to note the continuing discussions around the true meaning of access and its relationship with issues of demand as measured through utilisation. Another key concern is with the equity of access to services, something which most centralised health care systems aspire to and which is explicitly noted in the principal health strategy document, Quality and Fairness (Department of Health and Children, 2001). Access is defined as 'the ability to secure a specified set of healthcare services, at a specified level of quality, subject to a specified maximum level of personal inconvenience and cost, while in possession of a specified amount of information' (Goddard and Smith, 2001). The nearest to an agreed principle for equity is 'equal access to health care for those in equal need' (Oliver and Mossialos, 2004). Within core health geography texts, there is a further division of measurements of access into what might be referred to as 'spatial' and 'aspatial' elements (Joseph and Phillips, 1984; Khan and Bhardwaj, 1994). It is on the former approach that this paper will concentrate.

A key starting point for the modelling of acute hospital provision was the study carried out by Love and Lindquist (1995) in Illinois. They modelled the location of both acute general and specialist geriatric hospitals within the state against background demographic data on elderly populations. They used a GIS to model accessibility to both hospitals types using census block group centroids and five separate accessibility measures. The modelling used simple Euclidian distance and the outcome of the paper was to identify pockets of poor accessibility in rural parts of the state. This applied to general acute services and was even more apparent for specialist geriatric provision. The work of Brabyn and Skelly (2002) in 
New Zealand was also of relevance to an Irish case study. This was because it identified rural/urban issues in a country of similar size, geography and demographic structure. Again the outcomes clearly identified the rural/urban split, exacerbated in a country where topography and sparse road networks were a problem. Additionally, the example of New Zealand was relevant to Ireland due to the existence of a primate city, Auckland, which was directly comparable to the position of Dublin in Ireland. These issues of physical distance, travel time and transport networks were recurring themes in the literature (Lovett et al., 2002; Wang and Luo, 2005). The relationships between the distributions of existing primary and secondary services were also identified as key variables in other GIS-based modelling of health care provision (Rushton, 1999; Phillips et al., 2000; Haynes et al., 2003). Where this paper moves the process on is by combining travel-time modelling with a focus on the relative size of the hospital and linking this with specific population-groups to create a set of service specific and population-weighted accessibility measures. This was also closely linked to discussions within the GIS literature around the role of spatial interaction modelling, which incorporates considerations of service user location, travel mode and competing destination models all of which are relevant to the modelling approach used here (Fotheringham, Brunsdon and Charlton, 2000).

While these different GIS based approaches have been widely used elsewhere, data and information restrictions have prevented its extensive use in Ireland. This is not to say that there has been no use of GIS within health care in Ireland or indeed modelling of hospital accessibility in the country. The work of Horner and Taylor (1979) was particularly relevant in the pre-GIS era. The paper took a location-allocation approach to identifying changes proposed by the Fitzgerald Report (1968) to identify optimal sites for a set of major hospitals across the country based on then extant population distributions. Interestingly for later research, this earlier report also recommended a similar number of hospitals to the Hanly Report as being adequate; specifically twelve. Subsequently it would be fair to say that GIS use has been almost exclusively within the applied setting of health board reports and individual hospital work. A key article published in the on-line Irish Medical Journal by Teljeur, Barry and Kelly (2004) looked at similar issues to this paper. Their work was driven by the modelling of three specific aspects of service utilisation. These included admissions data on Accident \& Emergency, Heart Attacks and Road Traffic Accidents. They modelled the potential Post-Hanly impact on these services based on future scenarios. Methodologically, they used travel time but restricted it to those acute hospitals providing the aforementioned three services. There are some clear overlaps with this work but our emphasis is more directly on the modelling of geographical accessibility for acute hospitals as a whole. Additionally, this paper has a focus on the general population and does not model utilisation as this latter element is often a confounding factor when combined with accessibility measures in that it merges measures of 'supply' with proxy measures of 'demand', especially for use in a health policy setting (Oliver and Mossialos, 2004).

Other Irish health-based GIS examples include the individual modelling of proximity to landfill sites and the relationships between deprivation and health (Kelly, 1999; Boyle et al., 2004). As a result, there has been to date, a limited area-based modelling of service planning and provision at a national level. Such basic modelling is required to stimulate GIS use within Ireland. Indeed, the need for small area geographical analysis, including measurements of access to health services, has been explicitly identified as a requirement in the new strategic document on health information in Ireland (Department of Health and Children, 2004). This 
represents a valuable opportunity for GIS analysts to work explicitly in a series of applied health planning settings and this paper takes advantage of this opportunity.

\section{Data considerations}

\section{Methodology and data}

The initial data sets chosen for the modelling were drawn from a number of sources. The data on the distributions of populations were collected from the 2002 Census as administered by the Central Statistics Office (CSO). The choice of the elderly was based on the fact that they, as a population sub-group, were the highest users of acute services and accounted for a significant proportion of demand for health services (Hirshorn and Stewart, 2001). Demographic data were also collected at both Health Board/Authority and Electoral Division (ED) geographical level. This latter level was the lowest published aggregation in Ireland and had an average population of approximately 1,100 though this varied between urban and rural areas where the averages were closer to 3,000 and 500 respectively.

Information on the General Acute Hospitals in the country was gathered from the annual departmental publication on Health Statistics (Department of Health \& Children 2002). This report contained valuable information on individual hospitals and also helped with the identification of the hospitals to be used. Key data included a count of the number of beds in each hospital as well as a breakdown of bed provision by specialist medical service. Additional data included bed occupancy rates and outpatient numbers. This was valuable in providing information on the relative size and importance of individual hospitals (Figure 1). A third set of GIS data provided information on the road network for the country broken down from Motorway to minor road level, which was made available via the Ordnance Survey of Ireland (OSi). This was necessary to provide the foundation for travel-time modelling which, in conjunction with a set of look up tables for average speeds by road type, was used as a relational database item within the GIS. For example, motorways outside of urban areas were assigned a speed of 110 kilometres per hour, whereas inner-city road were assigned much lower speeds, typically 25 kilometres per hour.

Accessibility to hospitals was calculated using different measures. These were based initially on calculated network distances from each population centre to each hospital, which had traditionally been used as a proxy measure of access (Love and Lindquist, 1995). The distances were subsequently recalculated as travel times to provide a more realistic measure of access, a process common to much of the recent work in the area (Lovett et al., 2002, Martin et al., 2002). In the analysis presented here, there were 3,414 population centres that corresponded to the centroid of each ED in Ireland. The number of hospitals chosen included the 41 acute hospitals listed in the departmental report (Department of Health \& Children, 2002). The results of the network modelling showed that it was not possible to calculate distances to a number of ED's, primarily on islands. As a result, $9,090(0.23 \%)$ of the resident population were not included in the calculations but this had minimal impact of the modelling process. Additionally, the model was created solely for the Republic of Ireland as any crossborder movement to and from Northern Ireland was excluded as the two health systems operate independently and data access would be extremely difficulty (despite plentiful anecdotal evidence of use by residents of the Irish Republic of hospitals in Northern Ireland especially in Derry/Londonderry and Newry).

Certain spatial aspects of service provision in Ireland also affected the modelling. The distribution of Acute Hospital provision in Ireland is shown in Figure 1. The pattern of 


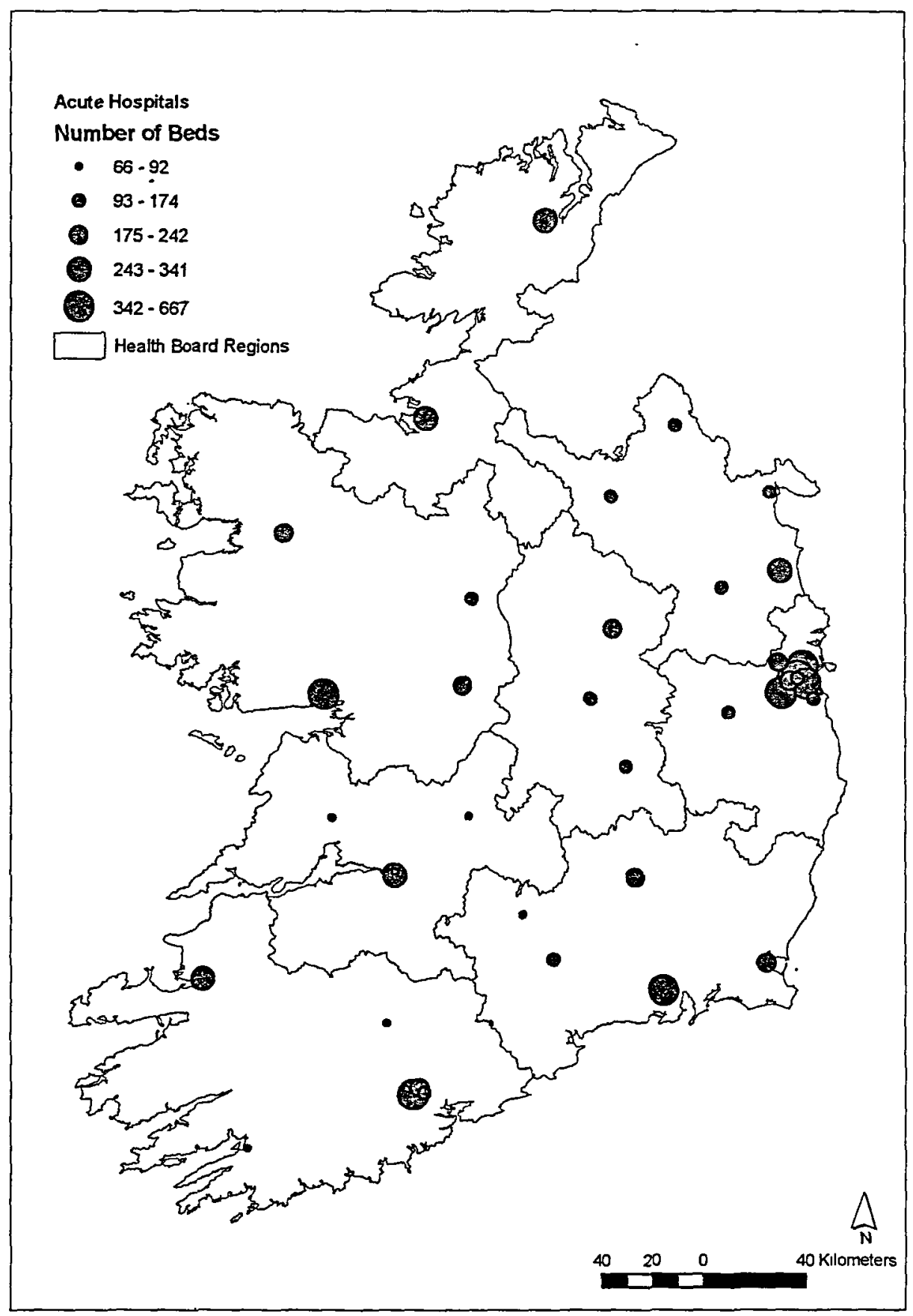

Figure 1: Location of acute hospitals and Health Boards in Ireland, 2004/5. 
provision was the result of both historical development and the dominance of the Greater Dublin Area in spatial and demographic terms (accounting as it does for around 35\% of the country's population). A second aspect was the distribution of the Health Boards, also illustrated in Figure 1. These boards essentially managed acute/secondary care at a regional level and also ran a number of hospitals, which varied by region. These Health Board funded hospitals were augmented by Voluntary Hospitals run by their own independent boards. Though administratively independent, these were funded primarily by public funds and made up the remainder of the national system of provision. Although Health Boards no longer formally exist with the introduction of the Health Service Executive (HSE) in 2005, the modelling in this study took place prior to this date and the then extant structures have been used.

\section{Methodology}

The modelling process was developed to represent a number of specific scenarios. The primary focus of the technical analysis within the GIS was to model geographical accessibility using a spatial interaction modelling approach. This was achieved by creating a measure of accessibility based on: potential demand (distribution of the general population by ED), available levels of service provision (Acute Hospital locations broken down by bed size), and available transportation links (the minor road network). We used a vector data analysis approach as this had also been used for analysing access to hospital facilities in the UK (Charlton et al., 2001; Martin et al., 2002). In order to calculate network distances, a geometric network based on Ireland's road network was created using ArcInfo. The calculated distance from each population centre (ED centroid) to each hospital was the sum of the distance from the centroid to the nearest node of a road segment, the shortest path within the road network, and the distance from the hospital to its nearest node of a road segment. The model was tien developed to incorporate travel time by utilising a relational database to match average national speeds against each road segment and its appropriate road type.

For the summary statistics, the average travel time to all hospitals for each population centre (expressed as an average for each ED) was used. Additionally, a more sophisticated accessibility measure was calculated to account for the population served as well as the size of hospital. This involved using a local address database (GeoDirectory) to match the populations within an ED to their closest network node and then summing this more accurate result to produce average ED values. This new accessibility measure was calculated for each $E D$, which in turn could be used for evaluating different scenarios of hospital reforms. It could also be used in statistical modelling to explain what determined accessibility to hospitals for the population as a whole. The formula used in the modelling is listed below. The higher the value of the measure, the higher the accessibility to hospital while the lower values essentially represent low accessibility to services. The formula listed below is referred to subsequently as a Spatial Accessibility Measure (SAM). The SAM score essentially provides a population-weighted accessibility score by ED to all acute hospitals in the country and is expressed as a range of values from 0.02 to 40,607 (though essentially this is an exponential range with a mean of 93.22).

The SAM measure was based on the notion that accessibility for any given place increased the greater the local population and the number and/or size of facilities in the system and decreased the greater the distances from the place in question to those facilities. The kinds of ED's that returned high values (over 50) were typically urban given their higher 
populations and close proximity to a number of hospitals. Rural areas on the other hand, were more distant from acute hospitals and were generally more sparsely populated and had scores of 5 or less. Within this broader methodology the ability to model accessibility for two other areas was also considered. The first of these was to focus in on a specific age group where a measure was calculated for older people aged 65 and over. As stated previously these were the population sub-group who would be most likely to be the heaviest users of hospital services. It was important therefore to see if the geographical distribution of this population sub-group affected its accessibility status when compared to the population as a whole.

$$
A_{a i}=1 / p_{i} \sum_{j} \frac{n_{j}}{p_{i} * d_{i j}^{2}}=1 / p_{i} . S A M
$$

where $A_{a i}$ is the accessibility in ED $i, n_{j}$ is the number of beds in each hospital: $p_{i}$ is the population at risk of this $E D$, and $d_{i j}$ is the network distance between the ED $i$ and each hospital $j$.

The second focus of the modelling had a much more policy-specific focus. While the proposals suggested in the Hanly Report are still some way from implementation (and depend substantially on the introduction of an extra 3,000 beds in to the system by the end of 2010), it also made a geographical modelling of the implications of proposed changes all the more pertinent. To this end, the modelling methodology also incorporated a number of scenarios based on the proposals (Department of Health and Children, 2003). The report suggested a three-way classification for future hospital provision as follows;

1) Major Hospitals serving populations of 350,000 to 500,000 with all main services. The aim is to have about 12 of these for the whole country. Most of the existing hospitals already have 10 or more specialisms, which seems to be a minimum cut-off point for consideration as a Major Hospital. The intention is that any of the current smaller hospitals which will be re-classified as Major will require a significant upgrade with the intention that the minimum bed size will be about 700 beds in future. A number of the current larger hospitals are already close to this figure.

2) General Hospitals. These are a few unique cases where their current size does not justify them being a Major Hospital but they serve areas, which are quite remote from the other proposed Major hospitals. As a result these hospitals may carry on providing existing services with the possibility of a small upgrade to distinguish them from local hospitals. This may mean the continuing provision of an A\&E service. The range of bed sizes for these hospitals was likely to be about 300 beds.

3) Local Hospitals. These are current smaller Acute hospitals with less than 10 specialisms that are to be effectively downgraded through the removal (in particular) of Accident \& Emergency services. For modelling purposes these hospitals were assigned an average bed size of 125 beds.

The final modelling scenarios incorporated these suggested modifications into the system and the results were calculated to reflect this spatially. The intention of this process was to see to what extent the upgrading of some hospitals and the downgrading of others might be 
reflected in a theoretical modelling of geographical access. In this way, an initial modelling of the potential gains and losses could be identified in a whole system setting. This was crucial to provide the first available evidence of potential spatial outcomes to both promoters and opponents of Hanly and to stimulate further debate.

\section{Statistical results.}

Results

The information contained in the first phase of accessibility modelling was initially summarised statistically. The results can be seen in Table $1 \mathrm{a} / \mathrm{b}$ below. Table la shows the cumulative shares of population broken down as quintiles. These show that for the 20 percent of the population nearest to the hospital the maximum distance is $2.68 \mathrm{~km}$, whereas for the upper quintile (the least accessible 20\%), this maximum distance has increased to $91.32 \mathrm{~km}$. It is also apparent from Table 1 that there is a huge leap between the 4th and 5th quintile. Another advantage of the modelling process is that breakdowns can also be produced for individual population sub-groups. From this we can see that for different age groups some variations exist. For the youngest age group, 0 to 14 years, the maximum distances are generally higher especially in the middle quintiles. For the second group of interest to our study, those aged 65 and over, there are also elevated distances in the middle three quintiles that suggested that this group has comparably lower rates of accessibility to acute services. This process is even more pronounced for the 80 and over age group. A final figure of interest was the statistic (bolded in Table $1 \mathrm{~b}$ ) that 80 percent of the population as a whole lived within $28.35 \mathrm{~km}$ of their nearest hospital which reflects a figure of $30 \mathrm{~km}$ as a distance commonly quoted as a 'target' in the health geography literature (Fortney, Rost and Warren, 2000).

\section{a) Current accessibility measures}

\section{Mapping Results}

The first set of spatial results produced an initial accessibility map, represented as a continuous surface, for the whole country (Figure 2). This map was created using travel time and the relative size of the hospitals (based on bed numbers) and also include a weighting based on the population within individual EDs. The map was essentially created to start off the process and identify a service base, which mapped spatial provision as the Spatial Accessibility Measure (SAM). The scores ranged from 0.02 (lowest accessibility) to $40,607.02$ (highest accessibility). The scores in themselves were artefacts of the formula that created them and were purely relative measures with exponential increases around urban areas. The average SAM score across the country as a whole was 93.22.

The results as expected show a general distance-decay effect across the country as a whole with a clustering of higher accessibility scores around the bigger cities (Cork, Galway, Limerick, Waterford) and especially the Greater Dublin Area. The areas that are poorly served tend to be the more remote western parts of the country along the coast from Cork/Kerry in the South West to Donegal in the North West. As well as greater variability in the West of the country, pockets of low accessibility could now be identified in the Midlands and parts of the South East as well. None of these patterns were overly surprising given existing clustering of populations and hospitals services.

\section{b) Sensitivity analysis (post-Hanly scenarios)}

The first phase of modelling was intended to represent the existing access to acute hospital care. A second aim of the research was to see if it was feasible to look at a number 
Table 1: Cumulative distributions of network distance to acute and geriatric Hospitals (km). .

\begin{tabular}{|c|c|c|c|c|c|}
\hline $\begin{array}{c}\text { Share of } \\
\text { population }\end{array}$ & $\begin{array}{c}\text { Total } \\
\text { Population }\end{array}$ & $\begin{array}{c}\text { People aged 0 } \\
\text { tol4 }\end{array}$ & $\begin{array}{c}\text { People aged 15 } \\
\text { to 64 }\end{array}$ & $\begin{array}{c}\text { People aged } \\
65 \text { and over }\end{array}$ & $\begin{array}{c}\text { People aged } \\
80 \text { and over }\end{array}$ \\
\hline Quintile & \multicolumn{5}{|c|}{ Kilometres to nearest hospital } \\
\hline 0.2 & 2.68 & 3.47 & 2.61 & 2.54 & 2.54 \\
\hline 0.4 & 6.58 & 7.68 & 6.16 & 6.98 & 8.17 \\
\hline 0.6 & 16.32 & 17.26 & 15.36 & 19.54 & 20.63 \\
\hline 0.8 & 28.35 & 28.60 & 27.62 & 30.80 & 32.20 \\
\hline 1 & 91.32 & 91.32 & 91.32 & 91.32 & 91.32 \\
\hline
\end{tabular}

\begin{tabular}{|c|c|c|c|c|c|}
\hline $\begin{array}{c}\text { Share of } \\
\text { population }\end{array}$ & $\begin{array}{c}\text { Total } \\
\text { Population }\end{array}$ & $\begin{array}{c}\text { People aged } \\
\text { 0 to 14 }\end{array}$ & $\begin{array}{c}\text { People aged 15 } \\
\text { to 64 }\end{array}$ & $\begin{array}{c}\text { People aged } \\
\text { 65 and over }\end{array}$ & $\begin{array}{c}\text { People aged 80 } \\
\text { and over }\end{array}$ \\
\hline Quintile & \multicolumn{5}{|c|}{ Kilometres to nearest hospital } \\
\hline 0.2 & 4.45 & 5.02 & 4.25 & 4.17 & 4.25 \\
\hline 0.4 & 12.45 & 16.27 & 11.48 & 19.56 & 23.58 \\
\hline 0.6 & 41.83 & 44.48 & 40.05 & 51.32 & 53.77 \\
\hline 0.8 & 74.68 & 75.66 & 73.88 & 79.42 & 83.21 \\
\hline 1 & 308.32 & 308.32 & 308.32 & 308.32 & 308.32 \\
\hline
\end{tabular}

of modelling scenarios based on the proposals contained within the Hanly Report. A number of modelling scenarios were developed based on the proposed hospital re-classifications. Again it should be emphasised that, apart from some pilot studies around Dublin and Limerick, the proposed changes have not yet been implemented. This was in part due to local opposition, which reflected the general health geographies literature around the political and contested nature of hospital closures (Lepnurm and Lepnurm, 2001; Barnett and Barnett 2003). Additionally, the service changes in the form of new bed provision have been a slow and equally contested process within the wider budgetary setting of national government (Curtis, 2004).

The principal quantitative element introduced into this second phase of the modelling was to introduce a bed-size based measure of the proposed new hospital classifications. This sensitivity analysis was carried out in two stages. The first stage used two scenarios to model a partial and full rollout of the Hanly proposals. Scenario 1 assigned a bed size of 700 to proposed major hospitals and left all other hospital bed sizes as they were. Scenario 2 incorporated a notional bed size based on the full Hanly proposals. In this version, proposed 'Major' hospitals were allocated 700 beds, 'General' hospitals were allocated 300 and 'Local' hospitals were modelled on the basis of a bed size of 125 . As a model these bed-sizes were then fed back into the GIS and revised SAM scores were calculated based on these scenario modifications.

The first results of this stage of this phase of modelling are illustrated in Figure 3 below. It shows a revised version of the original SAM measure (Figure 2) based around the current system and a partial Hanly rollout, with only the identified 'major' hospitals receiving an upgrade. The difference between the Current situation and both future scenarios is around 2,500 beds. This is relatively close in policy terms to the statement in the Report that an estimated 3,000 extra beds would be put into the system to make the proposals work 
(Department for Health and Children, 2003:61). Based on this purely geographical measure the proposed benefits of the Hanly proposal were arguably limited. The visual information presented in Figure 3 identified some small evidence of increased levels of accessibility in areas of previously low accessibility, though it also suggests increased benefits in and around urban centres that are currently well served. While some care must be taken in using the SAM scores given their relatively arbitrary nature, the relative levels of accessibility are increased to a maximum value of $95,638.15$. More usefully, the average SAM score for the country as a whole increased to 118.78 , reflecting the input into the model of around 2,630 extra beds.

The second stage of sensitivity analysis effectively modelled the potential impact of a full rollout of Hanly (Figure 4). By changing the nominal bed sizes to reflect the full set of theoretical proposals the SAM formula was reapplied to produce this new map. In the course of doing this the number of extra beds from the current situation was slightly reduced compared to Scenario 1, namely 2,577. Spatially some of the impacts relate to the reduction in the model of bed sizes in some of the local hospitals and this is reflected spatially in small reductions in accessibility around some of the rural hospitals such as Cavan, Kilkenny and Ballinasloe. In statistical terms the relative minimum and maximum values are almost identical to Scenario 1 though interestingly the average accessibility score has increased to 125.12. Given the caveats on these scores, it is still interesting to note that despite little visual evidence of change from Scenario 1 to Scenario 2, there is a suggestion from this score of greater improvements in accessibility across the country as a whole, were the full Hanly proposals to be developed.

Given this, the final map (Figure 5) is intended to reflect the value of taking a GIS approach to identify the implications of what spatial impacts might occur on accessibility, depending on whether Hanly is either partially or fully rolled out. In effect it provides strategic planiers and policy makers a set of theoretical outcomes as to the possibly winners and losers, if, when, and more specifically, how the Hanly proposals are actually implemented. This has regularly been identified as a particular strength of GIS-based modelling (Gatrell and Löytönen, 1998) in providing visual spatial outcomes to back up and illuminate statistical results. Figure 5 is broken down into two separate maps, indicating in turn the impacts and changes from the current situation with Scenarios 1 and 2 respectively. This suggests a pattern, which relates specifically to a policy-based outcome. In this case, the map has been simplified into 3 quintile categories with negative scores indicating a potential reduction in accessibility and positive scores indicating potential gains. In the case of Scenario 1 (Partial Hanly roll-out) the number of areas identified with negative scores has identified clusters in the centre and western seaboard. This would reflect the concentration in this scenario with increasing the size of urban hospitals and leaving the more rural provision as it stands. In the second map, reflecting the impact of Scenario 2 (Full Hanly roll-out), some of the same areas in the centre of the country continue to 'lose' accessibility. What is of particular interest in the second map are some potential improvements in accessibility in the western half of the country while there are pockets around the west of Dublin where a relative decline is likely. This reflects well the suggest introduction of a 'general' acute hospital category, particularly in Castlebar and the relative down-grading of some suburban hospitals such as Blanchardstown and Loughlinstown. 


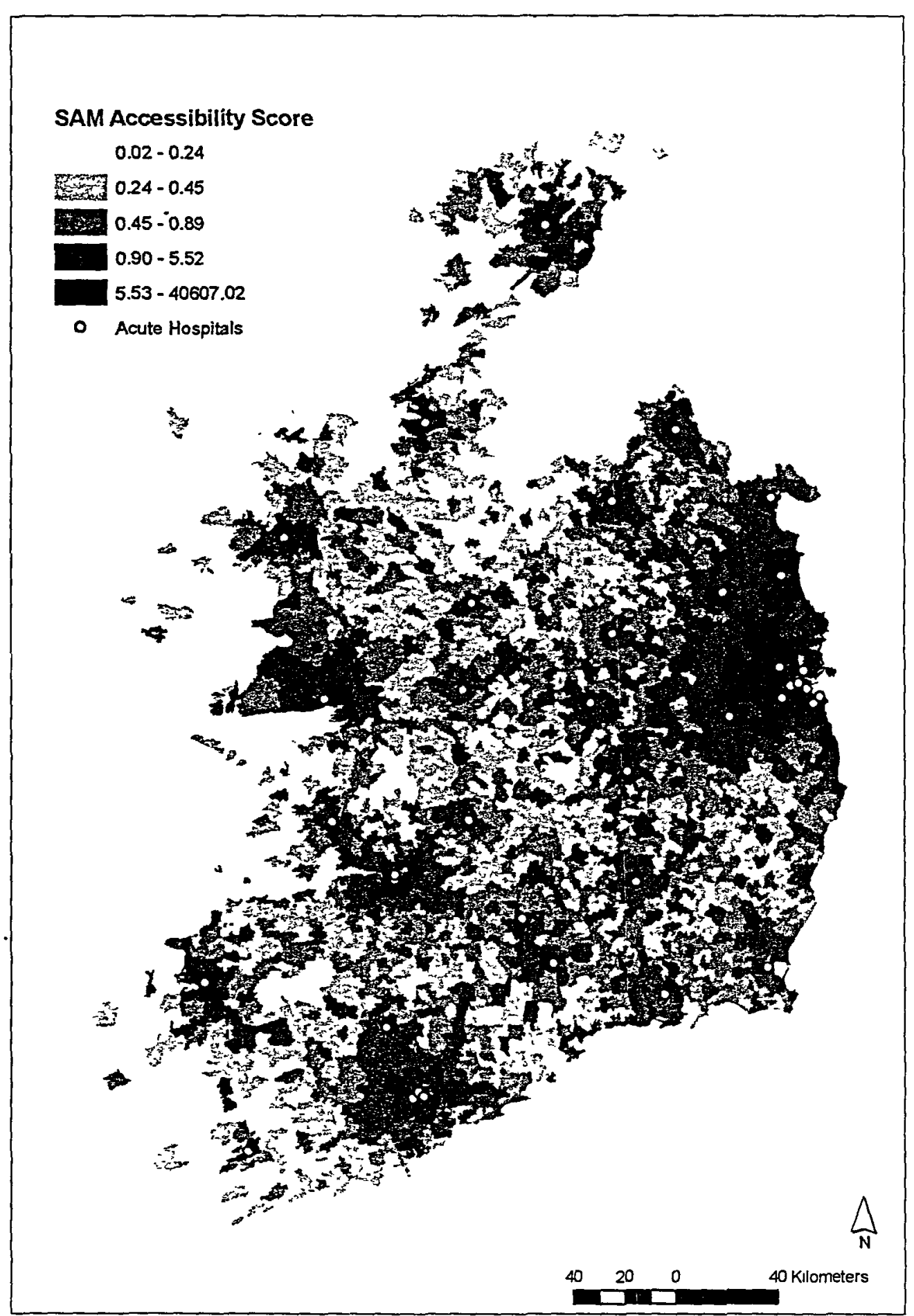

Figure 2: Accessibility to acute hospitals (SAM) 


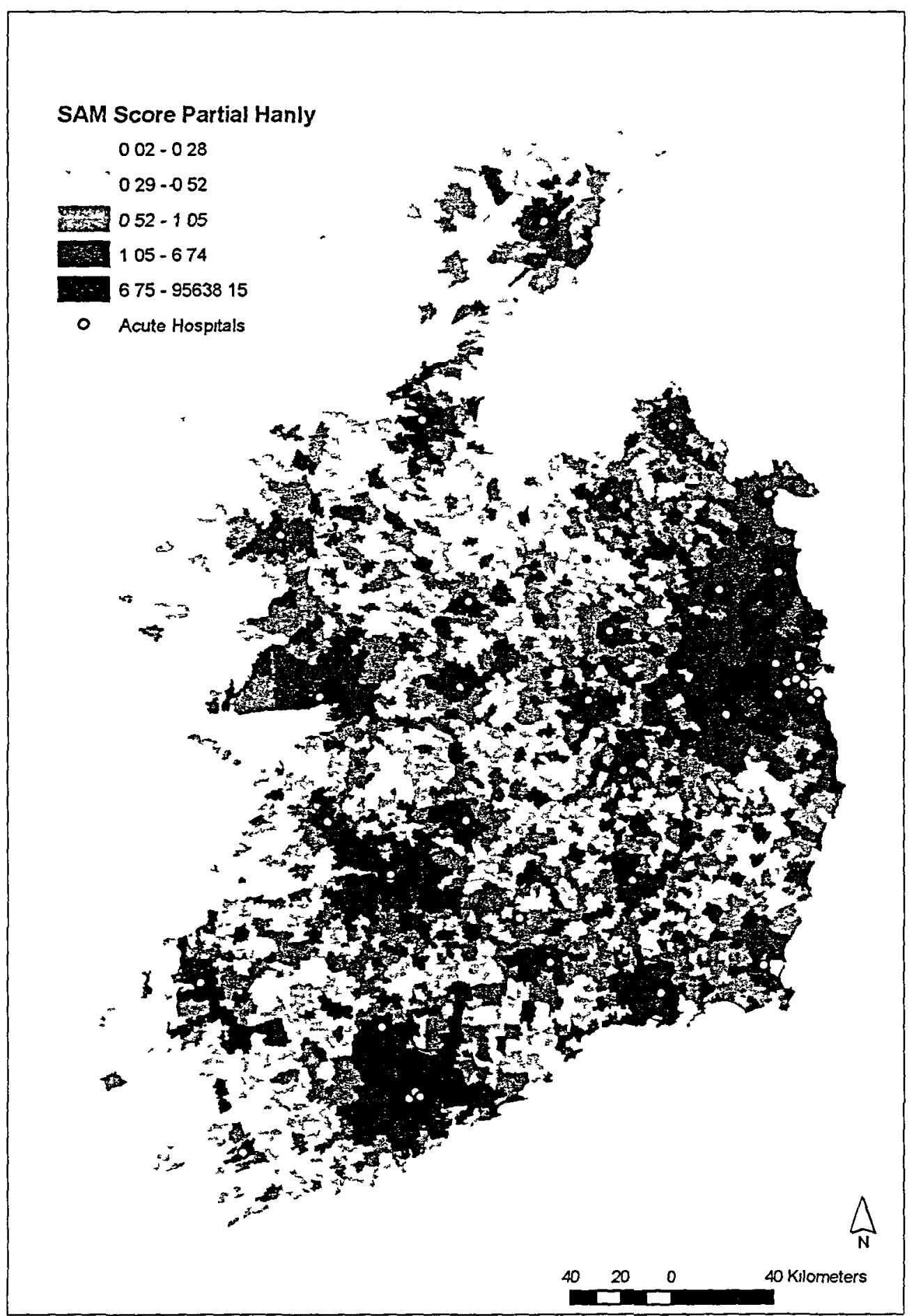

Figure 3 Sensittvity analysis of SAM Hanly scenario I (partial) 


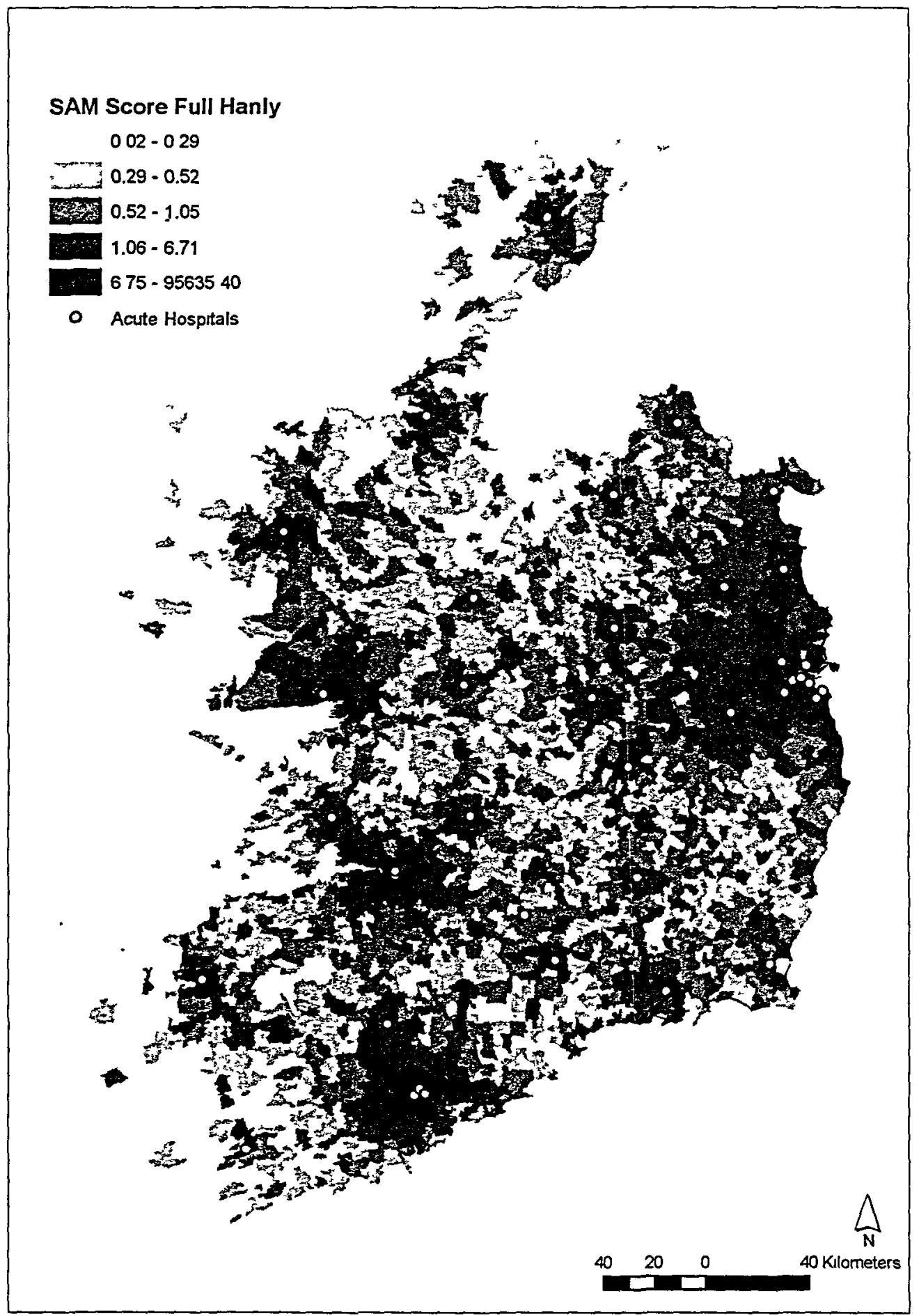

Figure 4: Sensitivity analysis of SAM Hanly scenario 2 (full) 

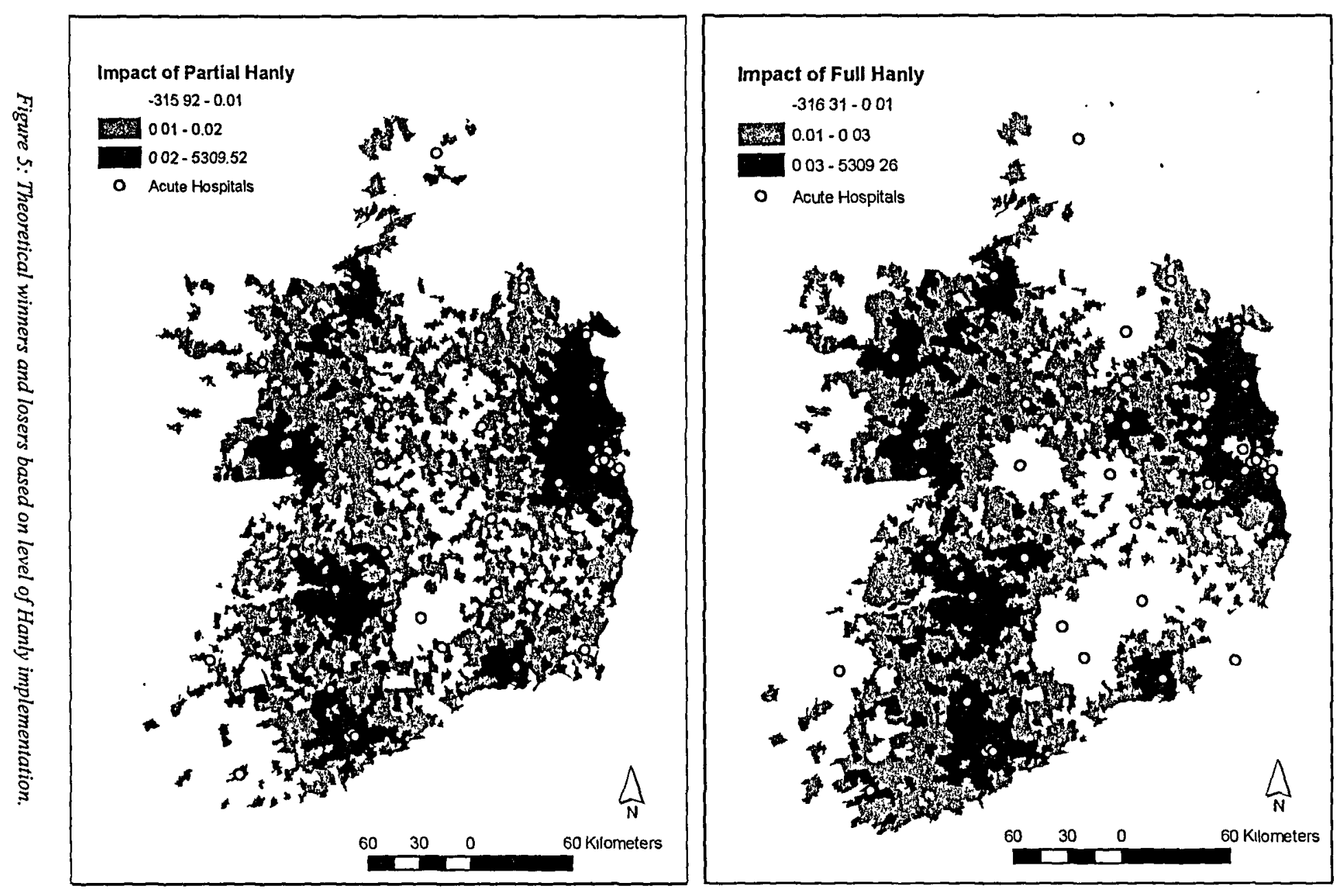


\section{Discussion and conclusion}

By modelling the spatial accessibility of both the existing and potential future configuration of services, some valuable information has been gleaned on the spatial implications of the Hanly Report. The population weighting, partially explored for the elderly population in the modelling, could in time be extended to other population groups such as young children, or those at high risk of degenerative disease. As a further development, greater sophistication could also be introduced to the model by taking into account additional district and community hospital provision, though the modelling of bed size would be more problematic in these more fluid health settings and the emphasis on acute provision would be less significant. However, even with the caveats noted above, and given that our specific focus was on acute services, we would argue that this initial modelling provided a useful estimation of the spatial implications of major strategic decisions. Using a GIS-based approach it was possible to model a number of different scenarios of arguably greater sophistication. As a final bonus, the implications of policy change were also factored into the modelling. There were a number of acknowledged problems with these types of modelling and drawing from the existing literature these are rooted in firstly, the technical issues associated with modelling point and areal vector data and secondly, the difficulties of representing the complexities of population health need and demand (Weber and Kwan, 2002; McLafferty, 2003). Additionally a number of different scenarios could be developed using different numbers of bed sizes to represent the proposed Major/General/Local hospital split and our choices are to some extent adaptable to future changes in bed size. Clearly this is only part of a fuller picture of the modelling of accessibility. Other factors such as the cost of capital services, staffing, and consultants, who are all highly significant are not incorporated in the spatial model (though they would be very difficult to operationalise). In fact these aspatial elements actually account for many of the delays in the development of the bed capacities, which the paper seeks to model. However, the value of the model clearly lies in the ability to plug in different configurations to model this part of the equation and to model any annual changes on the fly and to express the outcomes in a clear spatial manner. Much of the existing literature on measuring and modelling access also fails to fully develop this future modelling aspect in terms of fixed locations and prefers to focus on a more location-allocation based approach which is associated with specific local changes (Damiani, Propper and Dixon, 2005). Though a simple location-allocation process might identify optimal locations, the modelling in this paper is service provider driven and therefore simply models the implications of strategic decision-making rather than attempt to provide evidence for the best configuration of acute hospital provision.

Existing planning models of acute service provision in the Irish health care system are inadequately developed. By carrying out such modelling within a GIS framework, planners will be provided with some plausible and realistic outcomes, which can be fed back into the public and political arena and used as evidence-based information. This may be particularly valuable in planning a programme of national health care reform in the light of potential future demographic changes. This in turn will supply Irish health care planners with valuable additional spatial data with which to refine their future thinking. 


\section{References}

BARNETT, J.R. and BARNETT, P. (2003) 'If you want to sit on your butts you'll get nothing!' Community activism in response to threats of rural hospital closure in southem New Zealand., Health and Place, 9(2), 59-71.

BHANA, A. and PILLAY, Y.G. (1998). Use of the Geographical Information System (GIS) to determine potential access and allocation of public mental health resources in KwaZulu-Natal, South African Journal of Psychology, 28(4) 222-233.

BOYLE, E., JOHNSON, H., KELLY, A. and MCDONNELL, R. (2004). Congenital Anomalies and Proximity to Landfill Sites, Irish Medical Journal, 97(1). Available at: http://www.imj.ie/news detail.php?nNewsId=3028\&nVolld $=109$.

BRABYN, L. and SKELLY, C. (2002) Modelling population access to New Zealand public hospitals, International Journal of Health Geography, 1(1), 3-12.

BROWNELL, M., ROOS, N. and ROOS, L. (2001) Monitoring health reform: a report card approach, Social Science \& Medicine, 52 (5), 657-670.

CHARLTON, M., FOTHERINGHAM, S., and BRUNSDON, C. (2001). Analysing Access to Hospital Facilities with GIS, In: Clarke, G. and Madden, M. (eds) Regional science in business, Berlin and New York: Springer, $283-303$.

CHRISTIE, S. and FONE, D. (2003) Equity of access to tertiary hospitals in Wales: a travel time analysis, Journal of Public Health Medicine, 25 (4), 344-350.

CURTIS, S. (2004) Health and Inequality: Geographical Perspectives. London: Sage Publications.

DAMIANI, M., PROPPER, C. and DIXON, J. (2005) Mapping choice in the NHS: cross sectional study of routinely collected data, British Medical Joumal, 330 (7486), 284-288.

DEPARTMENT of HEALTH and CHILDREN (2001) Health Strategy: Quality and Fairness: $A$ Health System for you. Dublin: Government Publications Office

DEPARTMENT of HEALTH and CHILDREN (2002) Acute Hospital Bed Capacity, A National Review. Dublin: Government Publications Office

DEPARTMENT of HEALTH and CHILDREN (2003) Report of the National Task Force on Medical Staffing (Hanly Report). Dublin: Government Publications Office.

DEPARTMENT of HEALTH and CHILDREN (2004) Health Information: A National Strategy. Dublin: Government Publications Office.

EUROPEAN UNION (2000). Directive 2000/34/EC of the European Parliament and of the Council of 22 June 2000 amending Council Directive 93/104/EC concerning certain aspects of the organisation of working time to cover sectors and activities excluded from that Directive. Official Joumal L 195, 01/08/2000, 0041-0045. Brussels: European Commission.

FITZGERALD REPORT (1968) Outline of the future hospital system (The report of the Consultative Council on the General Hospital Services). Dublin: Stationary Office.

FORTNEY, J., ROST, K. and WARREN, J. (2000) Comparing alternative methods of measuring geographic access to health services, Health Services \& Outcomes Research Methodology, 1(2), 173184.

FOTHERINGHAM, A.S., BRUNSDON, C. and CHARLTON, M. (2000) Quantitative Geography: Perspectives on Spatial Analysis. London: Sage.

GATRELL, A.C. and LOYYTÖNEN, M. (1998) GIS and Health. London: Taylor and Francis.

GATRELL, A.C. (2002) Geographies of Health. Oxford: Blackwell.

GOODARD, M. and SMITH, P. (2001) Equity of access to health care services: Theory and evidence from the UK., Social Science and Medicine, 53(9), 1149-1162.

HAYNES, R., LOVETT, A. and SUENNENBERG G (2003) Potential accessibility, travel time and consumer choice: geographical variations in general medical practice registrations in Eastem England, Environment and Planning A, 35, 1733-1750.

HIRSHORN, B. A. and STEWART, J. E. (2001) Use of GIS for planning and service delivery to at-risk older populations, Gerontologist, 41 (SI 1), 243.

HORNER, A. A. and TAYLOR, A-M. (1979) Grasping the nettle - location strategies for Irish hospitals., Administration, 27(3), 348-370. 
JOSEPH, A. E. and PHILLIPS, D. R. (1984) Accessibility and utilization: Geographical perspectives on health care delivery. New York: Harper \& Row.

KELLY, A. (1999) Case studies in Bayesian disease mapping for health and health service research in Ireland, In: Lawson, A. et al. (eds) Disease mapping and risk assessment for Public Health. Chichester: John Wiley \& Sons, 349-63.

KHAN, A.A. and BHARDWAJ, S.M. (1994) Access to Healthcare: A Conceptual framework and its relevance to Health Care Planning, Evaluation \& the Health Professions, 17(1), 60-76.

LEPNURM, R. and LEPNURM, M.J. (2001) The closure of nural hospitals in Saskatchewan: method or madness? Social Science and Medicine, 52(11), 1689-1707.

LOVE, D. and LINDQUIST, P. (1995) The Geographical Accessibility of Hospitals to the Aged: A Geographic Information Systems Analysis within Illinois, Health Services Research, 29(6), 629651.

LOVETT, A., HAYNES, R., SUENNENBERG, G and GALE, S. (2002) Car travel time and accessibility by bus to general practitioner services: a study using patient registers and GIS, Social Science \& Medicine, 55(1), 97-111.

LUO, W. and WANG F. (2003) Measures of spatial accessibility to health care in a GIS environment: synthesis and a case study in the Chicago region, Environment and Planning $B, 30,865-884$.

MACNAMARA, C. (2004) The Hanly Report. A critique. Available at http://www.saveourhospital .com/CRITIQUE\%20HANLY.doc.

MCLAFFERTY, S.L. (2003) GIS and health care. Annual Review of Public Health, 24, 25-42.

MARTIN, D., WRIGLEY, H., BARNETT, S. and RODERICK, P. (2002) Increasing the sophistication of access measurement in a rural healthcare study, Health and Place, (8), 3-13.

O'DWYER, L. and BURTON, D. (1998) Potential meets reality: GIS and public health research in Australia, Australian and New Zealand Journal of Public Health, 22(7), 819-823.

OLIVER, A and MOSSLALOS, E. (2004) Equity of access to health care: outlining the foundations for action, Journal of Epidemiology and Community Health, 58, 655-658.

PHILLIPS, R.L., KINMAN, E.L., SCHNITZER, P.G, LINDBLOOM, E.J. and EWIGMAN, B. (2000) Using geographic information systems to understand health care access, Archives Of Family Medicine, 9(10), 971-978.

PROSPECTUS STRATEGY CONSULTANTS (2003) Audit of Structures and Functions in the Health System, 2003. Dublin: Stationery Office.

RUSHTON, G (1999) Methods to evaluate geographic access to health services, Journal of Public Health Management and Practice, 5(2), 93-100.

TELJEUR, C., BARRY, J. and KELLY, A. (2004) The Potential Impact on Travel Times of Closure and Redistribution of A\&E Units in Ireland, Irish Medical Journal, 97(6). Available at: http://www.imj.ie/news_detail.php?nNewsId $=3150 \& n$ Volld $=114$.

WANG F. and LUO, W. (2005) Assessing spatial and nonspatial factors for healthcare access: towards an integrated approach to defining health professional shortage areas, Health \& Place, 11(2), 131146.

WEBER, J. and KWAN, M.P. (2002) Bringing time back in: A study on the influence of travel time variations and facility opening hours on individual accessibility, Professional Geographer, 54(2), 226240. 